\title{
Computed tomography findings in partial seizures
}

\author{
A M B Minford, W I Forsythe
}

\begin{abstract}
The computed tomography findings in 82 children with partial seizures of unknown aetiology were reviewed. All had seizures with predominantly focal motor phenomena and none had abnormality on neurological examination. Findings on computed tomography were normal in 64 children $(78 \%)$ and abnormal in 18 children (22\%). Fourteen children had changes representing static pathology (mainly cerebral atrophy) which did not influence patient management but four had potentially correctable lesions (two tumours and two arteriovenous malformations). There were no correlations between seizure control, seizure duration, intellectual handicap, postictal weakness, electroencephalographic findings, and abnormality on the computed tomogram. In particular, none of these features were useful in predicting the presence of a tumour or arteriovenous malformation. It is concluded that a computed tomogram is indicated in every child wtih partial seizures.
\end{abstract}

The value of computed tomography in the investigation of epilepsy depends to a large extent on seizure type. For example, a low incidence of abnormality is found in primary generalised epilepsy ${ }^{1-3}$ and benign rolandic epilepsy ${ }^{4}$ but an abnormal computed tomogram is common in children with infantile spasms. ${ }^{56}$ In the investigation of partial seizures, few paediatricians would hesitate to ask for a computed tomogram if other neurological symptoms or signs were present. In their absence, the indication for computed tomography has been less certain. A recent onset of partial seizures in an adult without other clinical features raises concern about a possible space occupying lesion. Although it is acknowledged that the same event in a child is less likely to be due to sinister intracranial pathology, ${ }^{2}$ there are few data on the incidence of abnormal scans in children who present with partial seizures alone. Previous studies have tended to group together children with neurological signs, children without neurological signs, and children with known seizure aetiologies. ${ }^{7-11}$

In order to investigate the incidence of abnormal computed tomograms we have reviewed 82 children seen at Leeds or Bradford who had neither neurological signs or symptoms nor known aetiology for their partial seizures. Possible indicators of abnormality were sought by examining correlations between seizure duration, seizure control, findings on an electroencephalogram (EEG), postictal weakness, intellectual handicap, and findings on computed tomography.

\section{Patients and methods}

Although partial epilepsy can produce a variety of symptoms, we chose to review only those children whose seizures had predominantly focal motor phenomena rather than select patients on the basis of focal EEG abnormalities. This decision was based on the assumption that focal motor symptoms cause more concern about a possible structural lesion than other epileptic symptoms. For the purpose of this review, we did not differentiate between partial seizures of elementary symptomatology and partial seizures of complex symptomatology.

The 82 children presented between June 1978 and November 1988. Their age at onset of seizures ranged from 5 months to 14 years (mean age 5 years). All the children had partial seizures with well documented focal motor phenomena. Fifty one children had partial seizures only; 21 presented with partial seizures but later had generalised seizures; and 10 children presented with a generalised seizure but later had predominantly partial seizures. Six children had a history of febrile seizures which were prolonged in two cases.

Children with a known or suspected aetiology were excluded from the study. Children with severe mental retardation were excluded but not children with specific learning difficulties, mild or moderate mental retardation, or behaviour problems. Although none of the children had neurological abnormalities on examination, 18 children had brief transient focal weakness in the immediate postictal period. Children with benign rolandic epilepsy were not included because the absence of an underlying structural lesion is well recognised. ${ }^{4}$

In Leeds General Infirmary, computed tomograms were initially performed on the EMI 1010 scanner and later on an IGE 9800 scanner. In Bradford Royal Infirmary, a Siemens Sonaton DR third generation scanner was used. Six children had repeat tomograms and four children had angiography. All children had at least one EEG. Thirty five children, at the time of writing, have had one or more repeat EEG. In examining possible correlations between seizure duration, seizure control, intellectual handicap, EEG findings, and an abnormal computed tomogram, the $\chi^{2}$ test was used.

Results

The findings on computed tomography, which
Correspondence to: Dr Minford.

Accepted 15 January 1992 
Table 1 Findings on computed tomography in 82 children with partial seizures

\begin{tabular}{ll}
\hline & $\begin{array}{l}\text { No of } \\
\text { children }\end{array}$ \\
\hline Normal & 64 \\
Focal atrophy & 5 \\
Bilateral atrophy & 4 \\
Bilateral atrophy with calcification & 1 \\
Bilateral calcification & 1 \\
Focal calcification & 1 \\
Focal cortical enhancement & 1 \\
Infarction & 1 \\
Tumour & 2 \\
Arteriovenous malformation & 2 \\
Total & 82 \\
\hline
\end{tabular}

are shown in table 1 , were normal in 64 children (78\%) and abnormal in 18 children (22\%). Three of the latter group, one of whom showed bilateral atrophy, one bilateral atrophy with calicification, and one an old infarct, had normal tomograms initially. There was no significant difference in mean age for those with normal and those with abnormal scans $(5 \cdot 2$ years and 4.8 years respectively). Ten of the abnormal tomograms showed atrophic changes, the commonest abnormality being focal atrophy. Four children had varying degrees of bilateral atrophy ranging from slight ventricular enlargement suggesting central atrophy to generalised cerebral atrophy. The child with bilateral atrophy and calcification was neurologically normal when he presented with partial seizures at 1 year but three months later developed rapidly progressive developmental regression and intractable seizures, suggesting a neurodegenerative disorder. Extensive investigation did not produce a specific diagnosis, and when he died two years later permission for necropsy

Table 2 Numbers of children with prolonged seizures, difficult to control seizures, intellectual handicap, and postictal weakness

\begin{tabular}{llll}
\hline & $\begin{array}{l}\text { Normal } \\
\text { tomogram }\end{array}$ & $\begin{array}{l}\text { Abnormal } \\
\text { tomogram }\end{array}$ & $\begin{array}{l}p \\
\text { Value }\end{array}$ \\
\hline Prolonged seizure & 21 & 7 & $>0.5$ \\
Difficult to control seizures & 20 & 3 & $>0.1$ \\
Intellectual handicap & 13 & 6 & $>0.5$ \\
Postictal weakness & 14 & 4 & $>0.5$ \\
\hline
\end{tabular}

Table 3 EEG findings in children with normal and abnormal computed tomograms (figures in brackets are findings when all EEG findings are taken into account)

Initial EEG findingNormalAbnormalp tomogramtomogramValue

Normal32 (26) $8(6)>0.5$

Focal spike and wave $19(23) 8(8)>0$

Focal slow waves 1 (1) 1 (2) $>0.5$

Generalised spike and wave $7(8) 1(2)>0.5$

Bilateral slowing $5(6) 0 \quad>0 \cdot 5$

Total $64(64) 18(18)$

Table 4 Features of the four children with structural abnormalities on computed tomography

\begin{tabular}{llllll}
\hline & $\begin{array}{l}\text { Age at } \\
\text { presentation } \\
\text { (years) }\end{array}$ & $\begin{array}{l}\text { Prolonged } \\
\text { seizure }\end{array}$ & $\begin{array}{l}\text { Difficult } \\
\text { to control } \\
\text { seizures }\end{array}$ & $\begin{array}{l}\text { Intellectual } \\
\text { handicap }\end{array}$ & $\begin{array}{l}\text { Initial } \\
\text { EEG }\end{array}$ \\
\hline $\begin{array}{l}\text { Meningeal fibrosarcoma } \\
\text { Astrocytoma }\end{array}$ & $13 \cdot 5$ & No & No & No & Normal \\
Arteriovenous malformation & $6 \cdot 8$ & Yes & No & Yes & Normal \\
Arteriovenous malformation & 9 & No & No & No & Sow waves \\
\hline
\end{tabular}

was refused. The computed tomograms of two children showed calcification of the type found in the incomplete Sturge-Weber syndrome.

Although most of the abnormalities on computed tomography suggested static pathology, four children had structural lesions which were of therapeutic significance. Two children had tumours which were managed surgically: one tumour was found to be an astrocytoma of the right parietal lobe and the other a meningeal fibrosarcoma of the right parietal lobe. One child had an arteriovenous malformation of the left parietal region which was treated surgically. The other child with an arteriovenous malformation which involved the right presylvian fissure has been managed conservatively, although it is planned to treat this lesion by means of stereotactic radiotherapy. In both cases, the arteriovenous malformation was confirmed by angiography. In neither case was an intracranial bruit present. None of the four children with structural abnormalities complained of headache.

Approximately one third of all the children had one or more prolonged seizures of more than 30 minutes' duration, and approximately a quarter had seizures which were difficult to control. There were no statistically significant differences in the occurrence of prolonged seizures, difficult to control seizures, intellectual handicap, and transient postictal weakness between children with normal and abnormal tomograms (table 2).

Initial EEG findings are shown in table 3. Forty of the children $(49 \%)$ had normal initial EEG recordings. Almost the same incidence of abnormality on computed tomography $(20 \%)$ was found for children with normal initial EEG recordings as for all children in the series. Focal spike and wave was the commonest single abnormal finding. Focal slow waves, often taken as suggesting an anatomical abnormality, were present initially in one child with an abnormal computed tomogram. Of the eight children whose initial EEG recordings showed generalised spike and wave, six had partial seizures and only two had partial and generalised seizures. There were no statistically significant differences in any of the EEG findings between children with normal and abnormal computed tomograms. At the time of writing, 35 children have had one or more repeat EEG recordings. This slightly increased the number of the children with focal spike and wave but did not influence the $p$ values.

The clinical features and EEG findings of the four children with structural abnormalities are shown in table 4. One child had a prolonged seizure, one had postictal weakness, and none had difficult seizure control. Both children with tumours and one of the children with an arteriovenous malformation had normal EEG recordings; the latter had three normal EEG recordings.

Eleven children with initially normal computed tomograms had intractable seizures. Five of them had repeat tomograms of which three were normal, one showed generalised atrophy with calcification, and one showed an old infarct. Two children, in the early years of the 
study, had normal angiograms. The remaining four children have not yet had repeat scans. However, their tomograms were taken relatively late- - on average seven years after the onset of seizures. Another child in the series who had a normal initial computed tomogram was reinvestigated because of deteriorating performance at school. His repeat tomogram showed bilateral atrophic changes.

\section{Discussion}

This present study was confined to a review of children with partial epilepsy whose predominant seizure type was focal motor in nature. Children with abnormalities of the central nervous system and children with known or suspected aetiologies for their seizures were excluded. Not unexpectedly, we found that the majority of the children in our study had normal computed tomograms. Most of the children with abnormal tomograms had changes representing static pathology but four children had lesions of therapeutic significance. In drawing comparisons with previous studies, it is important to be aware that many of these studies included children with seizure types other than partial, children with abnormalities on neurological examination, and children with known or suspected aetiologies for their seizures. $^{7-11}$

In partial epilepsy, the frequency of abnormal findings on computed tomography is age dependent. Angeleri et al found abnormalities on computed tomography in $10 \%$ of childhood cases compared with $29 \%$ for patients between 19 and 50 years and $59 \%$ for patients over 51 years. ${ }^{12}$ The incidence of brain tumour is increased when partial epilepsy has its onset in adulthood. ${ }^{2}$

Lagenstein et al in a study of tomography findings in 309 children with different types of epilepsy, found that 64 (39\%) of 165 children with partial epilepsy had abnormal tomograms. ${ }^{10}$ Most of these changes were atrophic and only one child had a tumour. Yang et al found that $50 \%$ of 34 children with partial seizures of elementary symptomatology and $30 \%$ of 46 children with partial seizures of complex symptomatology had abnormal tomograms. ${ }^{9}$ Although focal atrophy was the commonest finding, four children had tumours. Both the series of Lagenstein and of Yang included children with abnormal neurological findings which may explain the higher incidence of abnormality than found in our study. Yang et al found that children with partial seizures and abnormal neurological findings were a high yield group, $65 \%$ having abnormal findings. 9

In a review of the findings of 115 epileptic children without neurological signs or symptoms, Patel et al found that nine out of 37 children (24\%) with partial epilepsy had abnormal tomograms. ${ }^{13}$ Of these nine cases, two had atrophy, four had infarction, two had porencephalic cysts, and one had an arachnoid cyst. None of these cases required surgical intervention and, although the number of children with partial seizures was relatively small, Patel concluded that computed tomography could be excluded from the investigation of children with seizures alone. A similar view was expressed by HarwoodNash who reviewed the tomographic findings of 695 epileptic children. ${ }^{14}$ However, he did not divided the children into seizure types.

In common with other authors, ${ }^{10}$ we found that atrophy was the commonest abnormality. It is interesting that six of the 18 children with abnormal tomograms had bilateral changes. Gastaut comments that this is not a rare finding in partial epilepsy because certain diffuse brain lesions can induce partial seizures due to the predominance of histological abnormalities in regions with a low seizure threshold. ${ }^{2}$ Although the finding of atrophy may suggest an earlier insult such as perinatal hypoxia and might possibly have prognostic value, it does not usually influence patient management. Although we did not find any cases of tuberose sclerosis, this condition was found in three children in the series of Yang $e t a l^{9}$ and one child in that of Lagenstein et al. ${ }^{10}$ This finding has important prognostic and genetic implications.

One of the main reasons for carrying out computed tomography is to exclude a neoplasm or other treatable lesion such as an arteriovenous malformation. Although these lesions are likely to present in a small minority of otherwise neurologically normal children, we had four children $(5 \%)$ with potentially correctable lesions. With the possible exception of focal slow waves in one case, there were no reliable pointers to the presence of these lesions.

Prolonged seizures, difficulty with seizure control, intellectual handicap, and postictal weakness were as common in children with normal tomograms. It is noteworthy that three of the children with structural lesions had normal EEG recordings. Surprisingly few of the 18 children with abnormal tomograms had slow waves. Yang found that patients with focal slowing showed a significant increase in abnormality. ${ }^{9}$ Sixty three per cent of his cases with focal slowing had abnormal tomograms.

We would disagree with the conclusions of Patel et $a l^{13}$ and Harwood-Nash ${ }^{14}$ that computed tomography should be reserved for children with seizures plus abnormality on neurological examination. We would agree with the view expressed by Wylie et al in their recent review of partial seizures that computed tomography is indicated in essentially all children with partial seizures. ${ }^{15}$ There have been several reports of unsuspected tumours or other structural lesions in children diagnosed by tomography. ${ }^{7}$ 16-18 For example, Holmes described two children, one with a glioma and the other with an arteriovenous malformation, both of whom had normal neurological examinations and EEG recordings. ${ }^{17}$ Most of the tumours described in such cases have been slow growing gliomas so that the presence of seizures for several years does not preclude the need for neuroradiological investigation. ${ }^{19}$ As tumours have also been found in some patients after an initially normal computed tomogram, 1920 further investigation either by repeat computed tomogram or by magnetic resonance imaging should be considered if seizures prove to be intractable. 
As a means of neuroradiological imaging, magnetic resonance imaging (MRI) is technically superior to computed tomography and has the added advantage that ionising radiation is avoided. Tumours, especially low grade astrocytomas, have been demonstrated on MRI when tomograms have been normal. ${ }^{21}$ However, MRI is often less readily available than computed tomography and is more expensive. ${ }^{22}$ It is unlikely to supersede computed tomography for some time as the initial standard neuroadiological investigation. We would advocate that all children with partial seizures should have a computed tomogram; but if seizures prove to be intractable in children with a normal tomogram, MRI should be considered as an alternative to repeated tomography.

1 Gastaut H, Gastaut JL. Computerized transverse axial tomography in epilepsy. Epilepsia 1976;17:325-36.

2 Gastaut JL. Computerized tomography in epilepsy: a five year experience. Electroencephalogr Clin Neurophysiol [Suppl] 1982;35:223-32.

3 Guberman A. The role of computed cranial tomography (CT) in epilepsy. Can $\mathcal{F}$ Neurol $S_{c i} 1983 ; 10: 16-21$.

4 Dalla Bernardine B, Chiamenti C, Capovilla G, Colamaria V. Benign partial epilepsies in childhood. In: Roger J, Dravet Benign partial epilepsies in childhood. In: Roger J, Dravet in infancy, childhood and adolescence. John Libbey Eurotext in infancy, childhood

5 Gastaut H, Gastaut JL, Regis $\mathrm{H}$, et al. Computerized tomography in the study of West's syndrome. Dev Med Child Neurol 1978;20:21-7.

6 Singer WD, Haller JS, Sullivan LR, Wolpert S, Mills C Rabe EF. The value of neuroradiology in infantile spasms f Pediatr 1982;100:47-50.

7 Bachman DS, Hodges FJ, Freeman JM. Computerized axial tomography in chronic seizure disorders of childhood. Pediatrics 1976:58:828-32.
8 Tomori N, Ishikawa A, Maruyama H. Computed tomography in childhood epilepsy. Folia Psychiatrica et Neurologica in childhood epilepsy.

9 Yang PJ, Berger PE, Cohen ME, Duffner PK. Computed tomography and childhood seizures disorders. Neurology tomography and

10 Lagenstein I, Sternowsky HJ, Rothe M, Bentele KHP Kühne G. CCT in different epilepsies with grand mal and focal seizures in 309 children: relation to clinical and electroencephalographic data. Neuropediatrics 1980;11 323-8.

11 Ladurner G, Fritsch G, Sager WD, Iliff LD, Lechner H Computer tomography in children with epilepsy. Eur Neurol 1980;19:180-4.

12 Angeleri F, Provinciali L, Salvolini V. Computerized tomography in partial epilepsy. In: Canger RF, Angeleri F, International Symposium. New York: Raven Press, 1980: 53-64.

13 Patel PJ, Kolawole TM, Mahdi AH, Qteishat WA. Computed tomography (CT) scan findings in children with seizures omography (CT) scan findings in childrer

14 Harwood-Nash DC. Computed tomography and seizures in children. 7 Neuroradiol 1983;10:130-6.

15 Wylie E, Rothner AD, Luders H. Partial seizures in children : clinical features, medical treatment and surgical considerations. In: Pellock JM, ed. Pediatr Clin North Am 1989;36:343-64

16 Lee TKY, Nakasu Y, Jeffree MA, Molyneux AJ, Adams CBT. Indolent glioma: a cause of epilepsy. Arch Dis Child 1989;64:1666-71.

17 Holmes GL. Electroencephalographic and neuroradiologic evaluation of children with epilepsy. In: Pellock JM, ed. Pediatr Clin North Am 1989;36:395-420.

18 Varma RR, Crumrine PK, Bergman I, et al. Childhood oligodendrogliomas presenting with seizures and low density lesions on computed tomography. Neurology 1983;33: 806-8.

19 Blume WT, Girvin JP, Kaufmann JCE. Childhood brain tumours presenting as chronic uncontrolled focal seizure tumours presenting as chronic uncontrol

20 Spencer DD, Spencer SS, Mattson RH, Williamson PD. Intracerebral masses in patients with intractable partial epilepsy. Neurology 1984;34:432-6.

21 Roach ES, Smith T, Terry CV, Riela AR, Laster DW. Magnetic resonance imaging in pediatric neurologic disorders. F Child Neurol 1987;2:111-6.

22 Elias-Jones AC, Jaspan T, Mellor DH, Worthington BS Magnetic resonance imaging in neurological disorders. Arch Dis Child 1990;65:922-9. 